\title{
Histological and Immunohistochemical Observations of Supramammary Lymph Node in Sheep and Goat
}

\author{
S. Senthilkumar ${ }^{1}$, T.A. Kannan ${ }^{1 *}$, Geetha Ramesh ${ }^{1}$ and D. Sumathi ${ }^{2}$ \\ ${ }^{1}$ Department of Veterinary Anatomy, Madras Veterinary College, Tamil Nadu Veterinary and \\ Animal Sciences University, Chennai-07, Tamil Nadu, India \\ ${ }^{2}$ Department of Veterinary Clinical Medicine, Madras Veterinary College, Tamil Nadu \\ Veterinary and Animal Sciences University, Chennai-07, Tamil Nadu, India \\ *Corresponding author
}

\section{A B S T R A C T}

Keywords

Madras Red sheep,

Boer local goat,

Supramammary

lymph node,

Histology,

Immunohistochemis try

Article Info

Accepted:

04 July 2019

Available Online:

10 August 2019
Lymph node involved in activation and maturation of lymphocytes and stimulates antigenic response against invading foreign substances. Supramammary lymph nodes had high significance in mastitis and other udder infections in small ruminants. For the present study, six supramammary lymph nodes of Madras Red ewe and Boer local she-goat were collected from Chennai corporation slaughter house. Histological and immunohistochemical observations were carried out. In both the species, supramammary lymph node was composed of two parts viz., parenchyma and connective tissue stroma. The lymph node was covered by a fibroelastic capsule composed of collagen, elastic and reticular fibres. Trabeculae originated from the capsule and divided the lymph node into many lobules. Parenchyma composed of an outer cortex and inner medulla. Cortex region contained several lymphoid follicles, which was made by outer mantle zone and inner germinal centre. Statistically no significant difference was observed in micrometric parameters such as capsule thickness, trabeculae thickness, lymphoid follicle diameter, germinal centre diameter and number of follicles per field (50x) between ewe and she-goat. Immunohistochemical staining for $\mathrm{CD}^{+}{ }^{+}$' $\mathrm{T}$ ' lymphocytes revealed their localization was found to be in interfollicular region and less in germinal centre. Medullary region showed sparsely located ' $\mathrm{T}$ ' lymphocytes.

\section{Introduction}

Lymph nodes are the secondary lymphoid organs situated along the course of lymph vessels and only lymphoid organ in the body with afferent and efferent vessels (Dellman and Brown, 1987). Histological organization and cell population of each lymph node reflect both the background activity of the immune system and local response of the node to small amounts of antigen and shows marked differences depending on their location in the body (Fawcett and Raviola, 1994). In ewes, One to three mammary lymph nodes are 
situated along the postero dorsal aspect of each mammary gland. These nodes varies in size, large node is kidney shape or crescenteric shape (Lee and Lascelles, 1969). In she-goats two to three mammary lymph nodes are situated caudodorsal to the udder. They related medially to the external pudental vessels (Getty, 2012). The nodes served as filters to remove or destroy the foreign substances and also provides a source of lymphocytes to fight infection affecting the mammary gland (Nickerson and Akers, 2011). Madras Red sheep is a medium-sized breed present in the northern regions of Tamil Nadu (Balasubramanyam et al., 2012). Boer local is a crossbreed goat evolved by crossing Boer and Local goats at Post Graduate Research Institute in Animal Sciences unit of Tamil Nadu Veterinary and Animal Sciences University (Palanivel et al., 2012). In general, the histology of various lymph nodes of ruminants is explored by various authors. But, no much work was carried out on the comparative histomorphometry and immunohistochemistry of supramammary lymph node of Madras Red ewes and Boer local she-goats. Hence, the present study was conducted to establish a basic data about histomorphometry and immunohistochemistry of supramammary lymph node of Madras Red ewes and Boer local she-goats.

\section{Materials and Methods}

The present study was conducted at the Department of Veterinary Anatomy, Madras Veterinary College. For histological studies, six supramammary lymph nodes from adult healthy Madras Red ewes and Boer local shegoats were collected from the corporation slaughterhouse, Chennai. After collection, the tissues were fixed in 10\% NBF (Neutral buffered formalin) and Bouin's fluid. For immunohistochemical staining six supramammary lymph nodes were used. Sections were stained by standard
Haematoxylin and Eosin (H\&E) method (Bancroft and Gamble, 2003), Masson's trichrome method for collagen and muscle fibres, Verhoeff's method for elastic fibres, Gomori's sliver method for reticulum (Luna, 1968) for the histological study.

\section{Immunohistochemistry staining method}

$3 \mu \mathrm{m}$ paraffin sections were cut and mounted on charged slides and incubated at $60-70{ }^{\circ} \mathrm{C}$ for 30 minutes. The sections were deparaffinized by two changes in xylene, dehydrated in absolute alcohol (two changes) and washed twice in distilled water. Heat mediated antigen retrieval was done using TRIS-EDTA buffer ( $\mathrm{pH} 8.5$ - 9.0). Then the sections were washed twice in distilled water for two minutes. Blocking of endogenous peroxidase was done with 3 per cent hydrogen peroxide for ten minutes. Then the sections were incubated in CD3 (ready to use) primary antibody in a moist chamber for one hour. Polyexcel HRP (ready to use) secondary antibody was added and incubated for 12 minutes and sections were washed three times in PBS. Diaminobenzidine (DAB) chromogen solution (1ml DAB buffer +1 drop DAB chromogen) was added and kept for two to five minutes and washed in distilled water. Gill's haematoxylin was used to counter stained the sections for one minute. Bluing the sections was done with running tap water for five minutes. Finally, sections were dehydrated through graded series of alcohol, cleared in xylene and mounted in synthetic mountant (Kannan et al., 2019).

Microscopic images were captured using the Leica microscope (CH9345 Heer brugg). Micrometry was done using the Leica application suite (LAS V4.4). The following parameters were measured in supramammary lymph node of ewe and she-goats viz., Capsule thickness, trabeculae thickness, diameter of lymphatic nodule and diameter of germinal 
center, number of nodules per field (50x). The data were subjected for statistical analysis. Independent ' $\mathrm{t}$ ' sample test was used to test the significant difference in micrometric parameters between adult ewe and she-goat. SPSS $^{\circledR} 26.0$ for Windows was used for statistical analysis of data.

\section{Results and Discussion}

\section{Histology}

In the present study, the histoarchitecture of supramammary lymph node in both Madras Red ewes (Fig. 1) and Boer local she-goats were found to be similar and resembled that of lymph node of other region.

The parenchyma was covered by a connective tissue capsule constituted of collagen (Fig. 2), elastic and smooth muscle fibres Capsule was made of fibro muscular tissue. Thickness of capsule was $112.54 \pm 28.38 \mu \mathrm{m}$ in ewe and $71.23 \pm 9.68 \mu \mathrm{m}$ in she-goat.

Trabeculae from the capsule passed into the parenchyma divided the node into many lobules. The fibrous trabeculae passed in between the lymphoid follicles, containing collagen, elastic (Fig. 3) and reticular fibres. Similar observations were made by Ganga Naik (2015) in Malnad Gidda cow's Supramammary lymph node. Thickness of the trabeculae was found to be $139.76 \pm 34.95$ $\mu \mathrm{m}, 179.71 \pm 36.80 \mu \mathrm{m}$ in ewe and she-goat respectively. In both ewes and she-goats trabeculae thickness was found to be more than the capsule thickness. A similar observation was made by Sarma et al., (2008) in Kagani goats. Reece reported that this trabeculae provided support for the entire lymph node and carried blood vessels along its path.

Parenchyma was made of an outer cortex and inner medulla. The cortex consisted of lymphoid follicles, each follicle showed the presence of the germinal centre made of lymphoblasts and large-sized lymphocytes and an outer mantle zone consisted of numerous small and medium sized lymphocytes (Fig. 4). In the present study, lymphoid nodule diameter in ewe was $414.56 \pm 28.92 \mu \mathrm{m}$ and $378.87 \pm 44.32 \mu \mathrm{m}$ in she-goat. In ewe and she-goat number of nodules per field (50x) was $3.16 \pm 0.70$ and $5.33 \pm 0.76$ respectively.

Table.1 Mean \pm SE of various micrometrical parameters in supramammary lymph node of Madras red ewes and Boer local she-goats

\begin{tabular}{|l|c|c|c|}
\hline \multirow{2}{*}{ Parameters } & \multicolumn{2}{c|}{ Mean \pm SE } & \multirow{2}{*}{ value } \\
\cline { 2 - 4 } & $\begin{array}{c}\text { Sheep } \\
(\mathbf{N}=\mathbf{6})\end{array}$ & $\begin{array}{c}\text { Goat } \\
(\mathbf{N}=\mathbf{6})\end{array}$ & \\
\hline Capsule thickness $(\boldsymbol{\mu m})$ & $112.54 \pm 28.38$ & $71.23 \pm 9.68$ & $1.37^{\text {NS }}$ \\
\hline Trabecular thickness $(\boldsymbol{\mu m})$ & $139.76 \pm 34.95$ & $179.71 \pm 36.80$ & $0.78^{\text {NS }}$ \\
\hline Lymphoid nodule diameter $(\boldsymbol{\mu m})$ & $414.56 \pm 28.92$ & $378.87 \pm 44.32$ & $0.67^{\text {NS }}$ \\
\hline Germinal centre diameter $(\boldsymbol{\mu m})$ & $214.98 \pm 27.09$ & $166.34 \pm 17.01$ & $1.52^{\text {NS }}$ \\
\hline Number of follicles per field $(\mathbf{5 0 x})$ & $3.16 \pm 0.70$ & $5.33 \pm 0.76$ & $0.06^{\mathrm{NS}}$ \\
\hline NS & & & \\
\hline
\end{tabular}

\footnotetext{
- No significant difference between sheep and goat $(\mathrm{P} \geq 0.05)$
} 
Fig.1 Photomicrograph of the supramammary lymph node of adult ewe

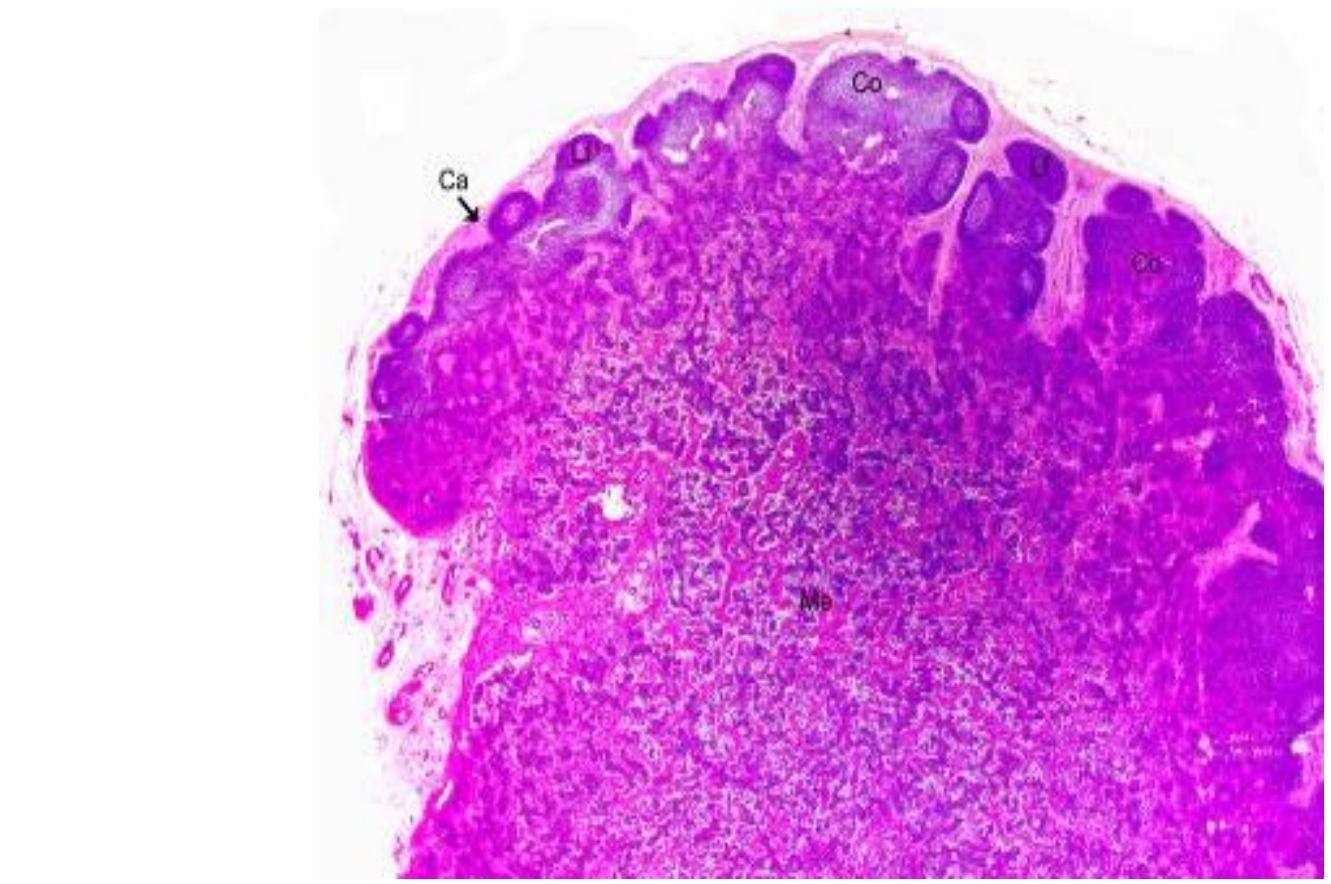

$\mathrm{Ca}$ - Capsule Co - Cortex Lf - Lymphoid follicle Me - Medulla

H\&E x 12.5

Fig.2 Photomirograph of the supramammary lymph node of adult ewe showing connective tissue capsule and parenchyma

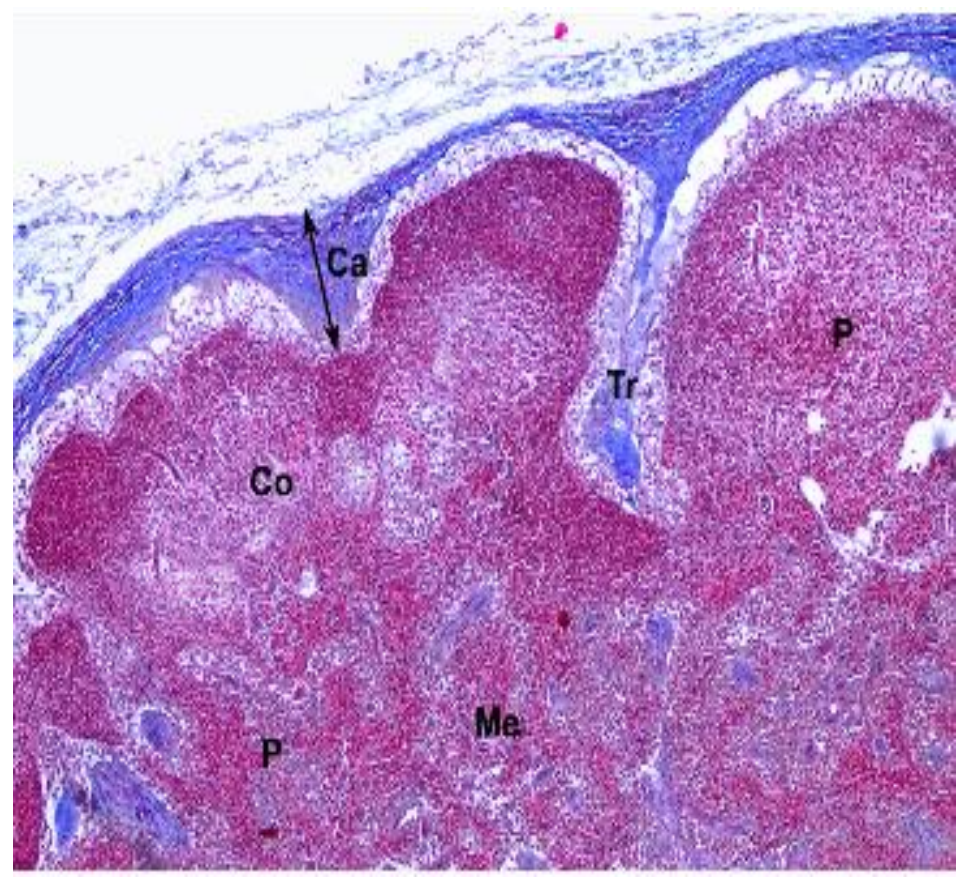

$\mathrm{Ca}$ - Capsule Co -Cortex Me -Medulla P - Parenchyma Tr - Trabeculae

Masson's Trichrome x 100 
Fig.3 Photomicrograph of the supramammary lymph node of adult she-goat showing the distribution of elastic fibres (arrows) in trabeculae

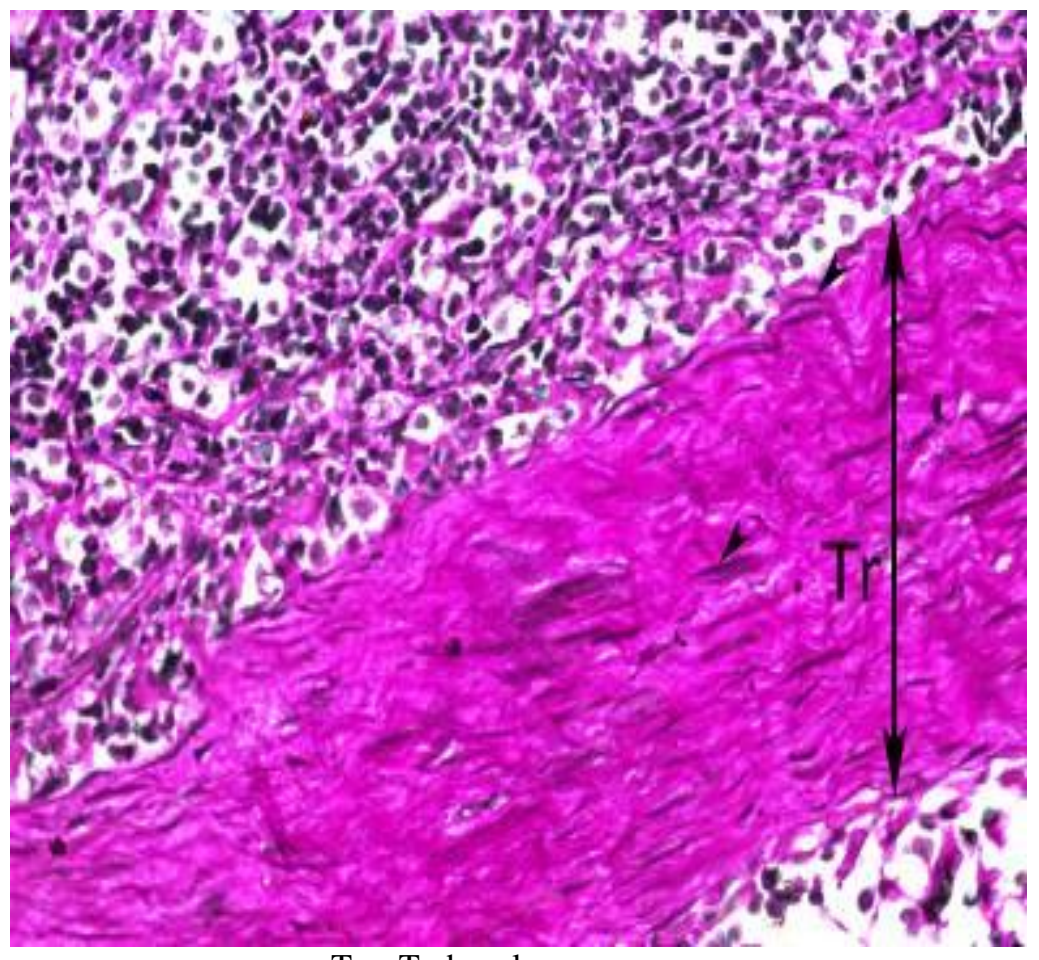

$\operatorname{Tr}-\operatorname{Trabeculae}$

Verhoeff's method x 400

Fig.4 Photomirograph of the supramammary lymph node of adult ewe showing germinal center

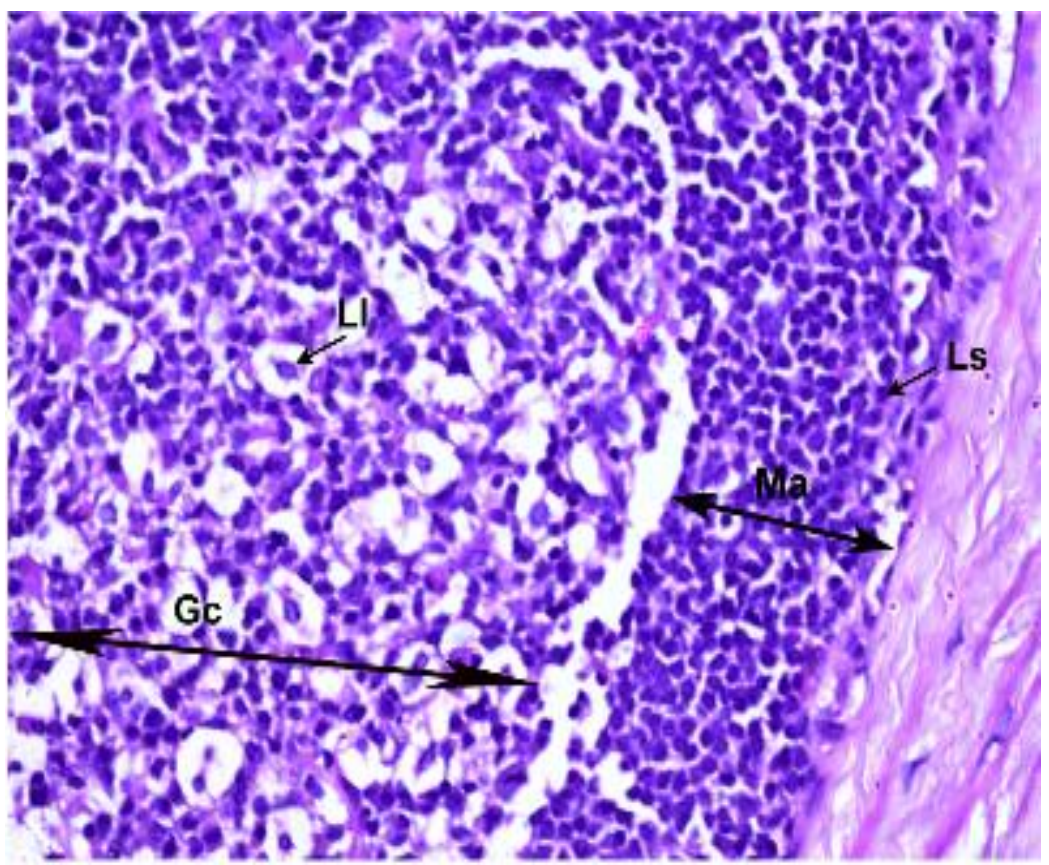

Gc - Germinal center Ll - Large lymphocytes Ls - Small lymphocytes Ma - Mantle zone 
Fig.5 Photomicrograph of the supramammary lymph node of adult she-goat showing the distribution of reticular fibres (arrow heads) in lymphoid follicle

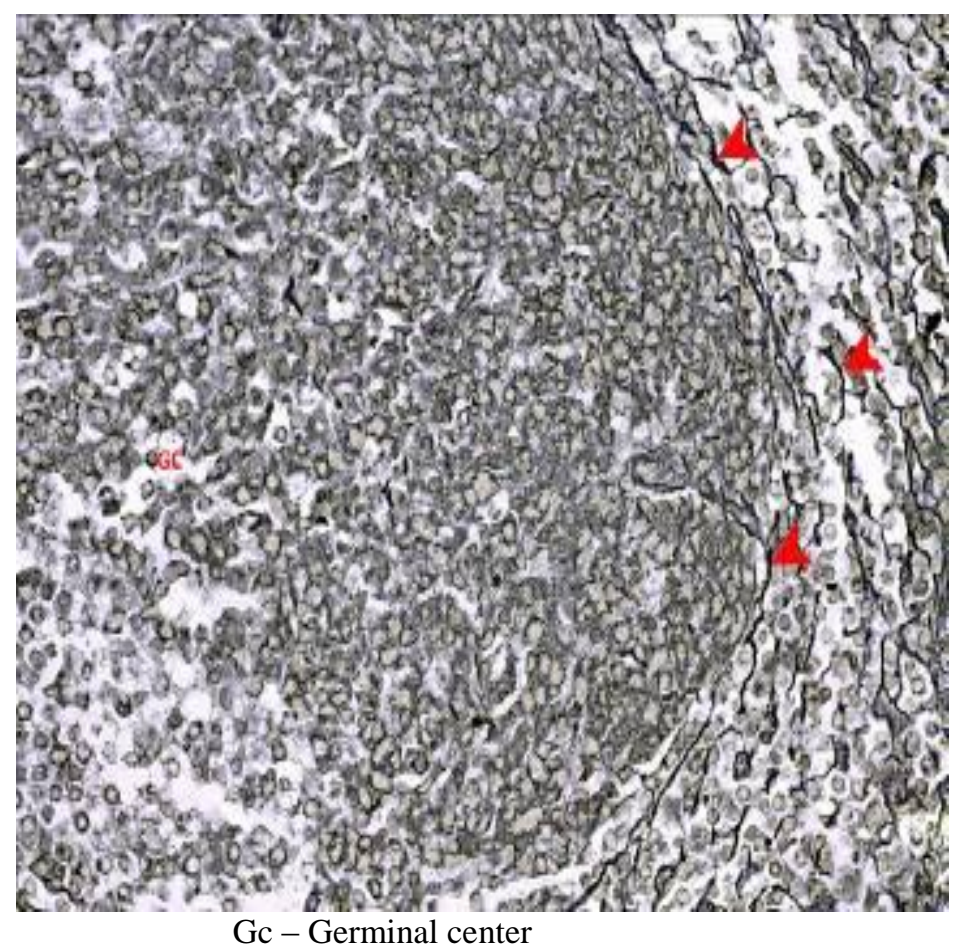

Gomori's method x 400

Fig.6 Photomirograph of the supramammary lymph node of adult ewe showing medulla

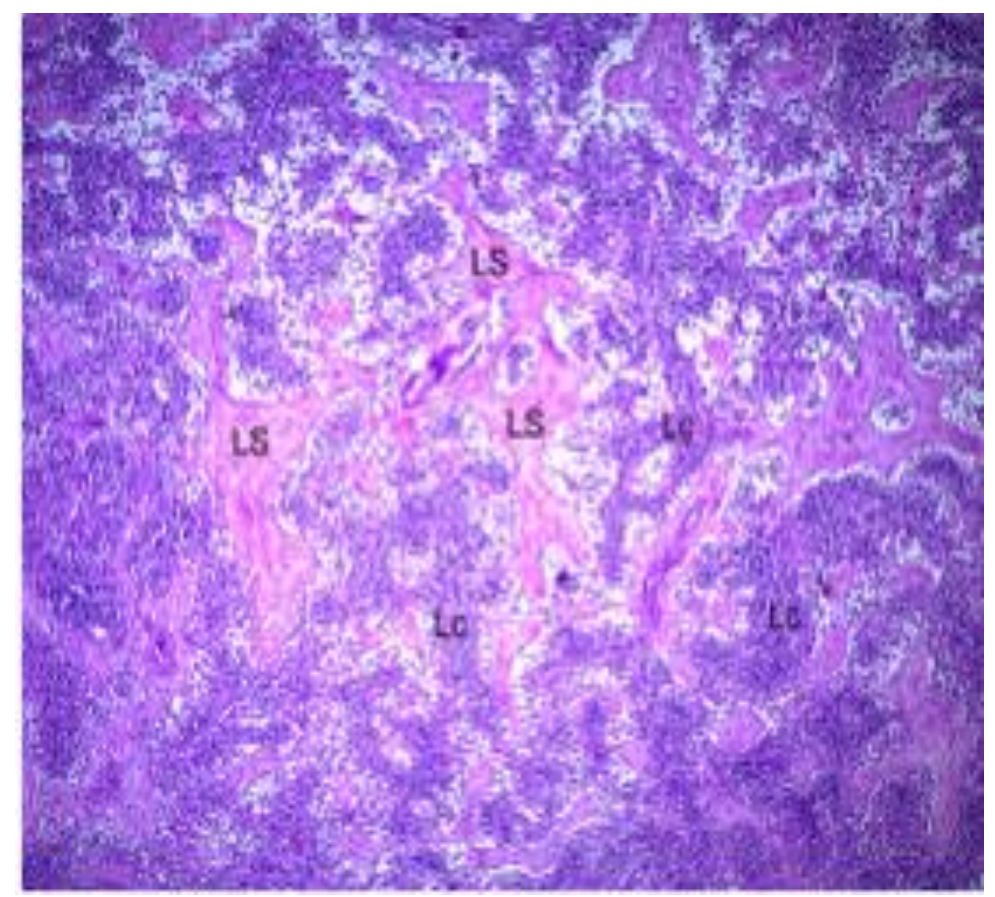


Fig.7 Photomicrograph of the supramammary lymph node of adult she-goat showing the distribution of ' $\mathrm{T}$ ' lymphocytes (brown coloured cells) in lymphoid follicle

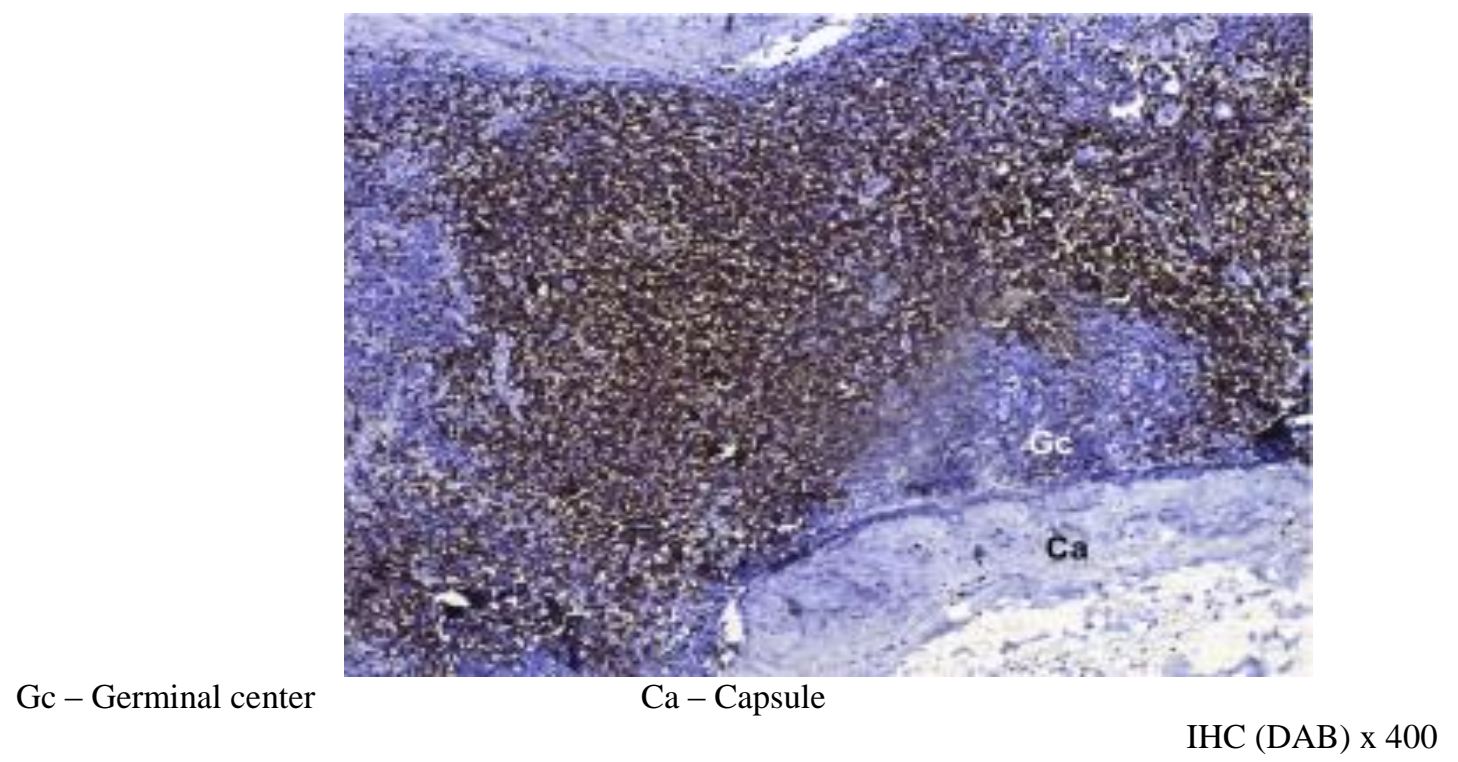

Fig.8 Photomicrograph of the supramammary lymph node of adult she-goat showing the distribution of ' $\mathrm{T}$ ' lymphocytes (brown coloured cells) in lymphoid follicle

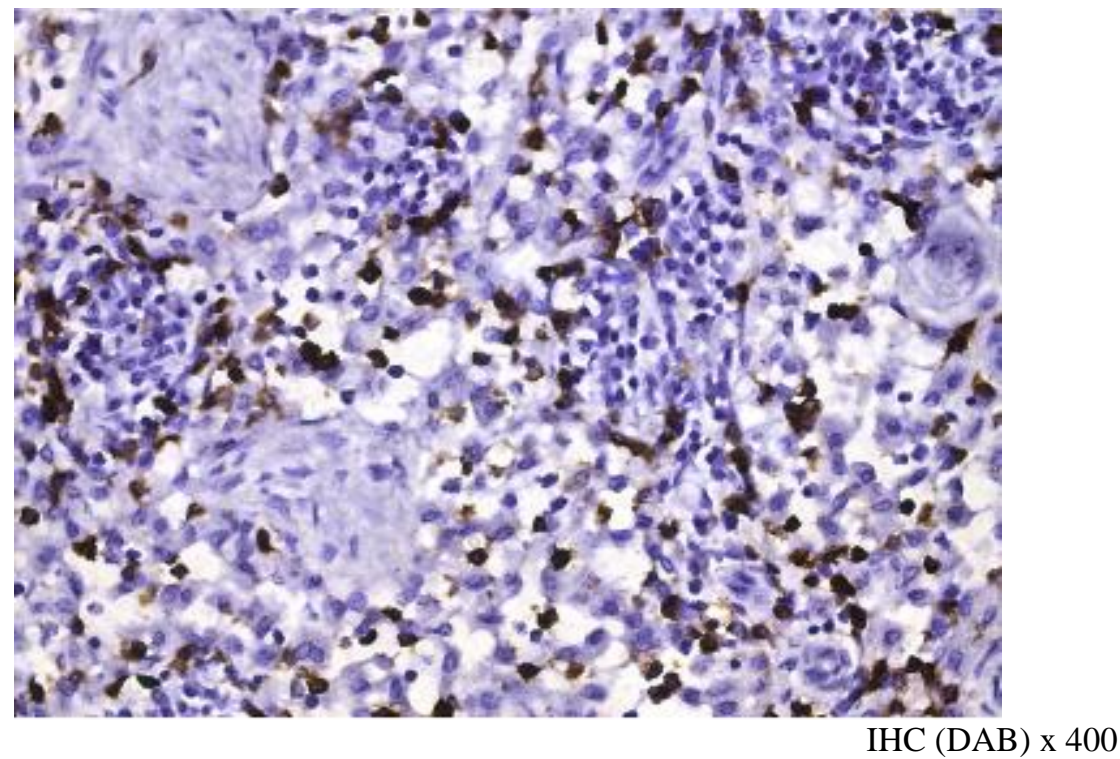

The nucleus of cells in the germinal centre was euchromatic, whereas it was heterochromatic in mantle zone. Germinal centre diameter was $214.98 \pm 27.09 \mu \mathrm{m}$, $166.34 \pm 17.01 \mu \mathrm{m}$ in ewe and she-goat respectively. In the lymphatic follicle, distribution of reticular fibres was more in the periphery and less in germinal centre (Fig. 5). The medulla of supra mammary lymph node was made of lymphatic cords separated by the lymph sinuses (Fig. 6). Similar observation was made by Sarma et al., (2008) in 
supramammary lymph node of Kagani goats. Various micrometric parameters viz., capsule thickness, trabecular thickness, lymphoid follicle diameter, germinal center diameter and a number of follicles per field (50x) were measured and given in Table 1. It was found that statistically, no significant difference exist between supramammary lymph node of Madras Red ewe and Boer local she-goat.

\section{Immunohistochemistry}

Immunohistochemical staining for $\mathrm{CD}^{+}$' $\mathrm{T}$ ' lymphocytes revealed the presence of more number of $\mathrm{CD}^{+}{ }^{+}$' $\mathrm{T}$ ' cells in the interfollicular region of cortex (Fig. 7) and mantle zone of the lymphoid follicle. Germinal centre of the follicle showed negative reaction, which indicated that the germinal centre consisted predominantly of ' $\mathrm{B}$ ' lymphocytes. In medulla $\mathrm{CD}^{+}$' $\mathrm{T}$ ' cells were sparsely located (Fig. 8). These results were in concurrence with the findings of Christophe et al., (2008) in bovine temporal and parotid lymph node and Huang et al., (2018) in mandibular, bronchial and mesenteric lymph nodes in yaks and Kannan et al., (2019) in hemal nodes of Indian buffalo. Soltys and Quinn, (1999) explained that, these lymphocytes got activated and migrate to the site of infection and fight against the bacterial pathogens during occurance of mastitis in udder of cows.

\section{Acknowledgements}

The author acknowledges the Dean, Madras Veterinary College and the authorities of Tamil Nadu Veterinary and Animal Sciences University, Chennai for providing necessary facilities to carry out the research work.

\section{References}

Bancroft, J.D and M. Gamble, 2003. Theory and Practice of Histological Techniques. 5th Edn., Churchill and
Livingstone, New York, 593-620.

Fawcett, D.W and E. Raviola, 1994. A Textbook of Histology. $12^{\text {th }}$ edition. Chapman and Hall, New York, 449.

Huang, Y., Y. Cui, S. Yu, J. He, Q. Zhang, P. Liu, Y. Pu, J. Sun and X. Kang, 2018. Comparison of histological characteristics and expression of CD3 and CD79a among the hemal nodes, lymph nodes and spleens of Yaks. Histology and Histopathology, 3 - 28.

Kannan, T.A., R. Gnanadevi, S. Senthilkumar and Geethe Ramesh, 2019. Histomorphometric and Immunohistochemical datails of hemal nodes in Indian Buffalo. Journal of Entomology and Zoology Studies, 7(2): 384-387.

Lee, C.S and A.K. Lascelles, 1969. Distribution of Lymphatic Vessels in Mammary Glands of ewes. Am. J. Anat., 126: 489-496

Luna, 1968. In "Manual of Histological Staining Methods of the Armed Forces of institute of Pathology", 3rd Edn. The Blackistone Div. Mcgrow-Hill Book Co., New York.

Naik, G.S., 2015. Gross and histomorphological studies on the mammary gland of Malnad gidda cows in Karnataka. (Ph.D. Thesis), Karnataka Veterinary Animal and Fisheries Sciences University, Bidar, India.

Nickerson, S.C and R.M. Akers, 2011. Mammary gland, Encyclopedia of dairy sciences. 2nd edition. 3: 328-337.

Palanivel, K.M., P. Muthusamy, K. Sureshkumar and P. Kumarasamy, 2012. Mortality in Boer Graded Local Goats in Tamil Nadu. Indian Vet. J., 89(12): $22-23$.

Sarma, K., J. Devi and A.K. Srivastava, 2008. Morphological and morphometrical study of the superficial lymph nodes of Kagani goat (Capra hircus) in Jammu region. Folia Veterinaria, 52(3-4): 119- 
123.

Soltys, J and M.T. Quinn, 1999. Selective Recruitment of T-Cell Subsets to the Udder during Staphylococcal and Streptococcal Mastitis: Analysis of
Lymphocyte Subsets and Adhesion Molecule Expression. Infect Immun., 67(12): 6293-6302.

\section{How to cite this article:}

Senthilkumar, S., T.A. Kannan, Geetha Ramesh and Sumathi, D. 2019. Histological and Immunohistochemical Observations of Supramammary Lymph Node in Sheep and Goat. Int.J.Curr.Microbiol.App.Sci. 8(08): 74-82. doi: https://doi.org/10.20546/ijcmas.2019.808.009 